\title{
Cine chino: nacionalismos, cuasi- nacionalismos y (trans)nacionalismos/ localismos en el cine de la República Popular China, Taiwán y Hong Kong
}

\author{
LaI SaI Acón Chan \\ Instituto Confucio \\ Universidad de Costa Rica
}

\begin{abstract}
Resumen
En los círculos no cinéfilos la separación entre cine taiwanés, de Hong Kong y chino no parece clara. Así, un recuento cronológico de sus industrias fílmicas revelará también los convulsos movimientos históricos que dieron origen a las tres áreas geográficamente diferenciadas, las cuales comparten una identidad etnográfica y un origen comunes, pero procesos divergentes de desarrollo económico y político que, al final, han marcado cada cine nacional con rasgos distintivos.
\end{abstract}

Palabras claves: cines nacionales, industrias fílmicas, nacionalismos, historia, China, Taiwán, Hong Kong, crecimiento económico, sistemas políticos

\begin{abstract}
In non cinephile circles the separation among Taiwanese, Hongkongese and Chinese (from the People's Republic of China) cinemas might not be clear-cut. Thus, a chronological account of their film industries will also reveal the convoluted historical movements that gave rise to three distinctive geographical areas that share a common ethnographical identity and origin, but divergent processes of economic and political development that in the end endowed each national cinema with distinctive traits.
\end{abstract}

Key words: national cinemas, film industries, nationalisms, history, China, Taiwan, Hong Kong, economic growth, political systems 
$\mathrm{S}$ in duda, al referirse al cine chino, surge la interrogativa de a cuál de las tres industrias de cine chino actuales alude la frase en cuestión. Probablemente para un espectador poco experimentado, el cine chino se constituye en uno solo. Y siguiendo esta lógica, proviene de una sola industria cinematográfica. Lo cierto es que al hacer mención del cine chino, es inevitable aludir a tres cinemas nacionales o cuasinacionales y hasta transnacionales o translocales: el cinema de la continental República Popular China (RPC), el de la insular República de China en Taiwán (RCT) y el de la antigua colonia británica de Hong Kong, hoy conocida como una región administrativa especial de la RPC.

Es mi intención en este articulo hacer un análisis de estas tres tradiciones de cine para establecer origen, características, similitudes y diferencias, evolución y naturaleza (trans/cuasi)nacional/local de cada una de ellas. Ciertamente, eventos históricos de mayor magnitud favorecen la conformación de tres industrias de cine chino que desarrollan características distintivas y que en ciertos momentos convergen y en otros divergen. El fin de la era de Mao Tze Tung, en el año 1976, no solo puso fin a veintisiete años de separación entre los chinos del continente, de Taiwán y de Hong Kong, sino que también coincidió con un boom económico primero en Taiwán y Hong Kong, territorios en donde el capitalismo ya operaba, y después en la China continental gracias a las reformas económicas impulsadas por Deng Xiaoping, quien acuñó la memorable frase "No importa si el gato es gris o negro, lo que importa es que cace ratones", en referencia a un cambio de postura ideológica de la China de Mao a una China que eventualmente desarrolló un socialismo con características chinas. Es decir, una China más abierta al mundo occidental y a las ventajas de sus sistemas políticos pero siempre conservando la base política y económica que había regido los destinos de millones de chinos desde 1949.

\section{Origen del cine en China y poste- rior ramificación en tres vertientes}

Según Sheldon Hsiao-Peng Lu, en 1896 comienza en China un consumo y distribución de películas de carácter transnacional (2) en el sentido de fuerzas que cruzan fronteras nacionales, geopolíticas y lingüísticas (citado en Zhang 136). Para Zhang es también válido discutir el carácter translocal de esta naciente industria, especialmente cuando Taiwán y Hong Kong se ven involucrados. Es decir, ya desde sus inicios el cine chino se vislumbra como un cine que trasciende los límites artificiales de la nación, en algunos casos paradójicamente atravesando límites que son locales y a la vez nacionales. Tal es el caso de Hong Kong, territorio chino cedido a los ingleses en 1842, que por circunstancias especiales se desarrollaría como una cuasinación y que en 1997 adquiriría estatus de región administrativa especial de la República Popular China (RPC), revirtiendo así su destino de una manera poco usual para territorios desocupados por un poder imperial. Tal es el caso de la República de China en Taiwán, una isla al sur de China continental que desde el siglo XVII ha sido ocupada por los portugueses, por los chinos, por los japoneses y por los nacionalistas chinos 
en 1949, y que en la actualidad es una república soberana sin representación en la O.N.U. y considerada provincia rebelde por la RPC.

Tan solo un año después de que los hermanos Lumière dieran a conocer su invención, llega el cinematógrafo a Shanghái. En adelante y hasta el año 1949, algunas producciones cinematográficas extranjeras fueron regularmente proyectadas en salones de té y teatros. A pesar de que entre los años 1905 y 1915 se producen en China los primeros intentos por formar un discurso cinematográfico propio, lo cierto es que desde sus inicios fueron eventos que incluyeron capital de socios extranjeros como el judío norteamericano Benjamin Brodsky, fundador del estudio Asia Film Company. Aun cuando un $90 \%$ de las películas exhibidas en China provenían de otras latitudes, hubo intentos en Shanghái, Hong Kong y Guangzhou por establecer una industria de cine china. Brodsky se asoció a Li Minwei, un documentalista y fotógrafo mejor conocido hoy en día por el metraje que produjo de Sun Yat Sen, fundador del Partido Nacionalista o Kuomintang (KMT), para producir el primer filme en Hong Kong, entonces territorio británico, con su compañía Minxin. Comienza así una industria de cine chino que debido a coyunturas históricas se bifurcaría en tres industrias separadas. Menciona Yeh que antes de 1930, el cine chino rara vez operó a escala nacional: "Chinese cinema in its formative period was .. . not a national enterprise self-contained within the boundaries of the nation-state but a diasporic venture connecting the Chinese populations in Shanghai, Hong Kong, Sin- gapore [sic], Southeast Asia, Australia, and North America." (citado en Zhang 137). Es decir, antes de ese año el cine chino poseía un sabor local aun cuando hubiera traspasado sus fronteras. No solo no se exportaba a audiencias no chinas, sino que cuando era llevado a otros países se destinaba al consumo de comunidades de chinos de ultramar. Por tales razones no contaba aún como proyecto nacional.

Los años de oro del cine chino están marcados por los primeros grandes estudios de cine, los primeros actores con estatus de estrellas y las primeras películas chinas que obtuvieron una gran recepción por parte del público. Con respecto a géneros, se desarrolló una industria enfocada en el entretenimiento como se puede apreciar en el cine de ficción, en historias de artes marciales y fantasía, y los melodramas basados en óperas chinas. Sin embargo, con la ascensión al poder de los nacionalistas en 1927, se utiliza el cine para propagar causas políticas. El mismo Li Minwei crea el eslogan "Salvemos la nación a través del cine" (Teo 4). A la vez, el gobierno nacionalista instaura una junta de censura que reguló no solo imágenes degradantes de películas extranjeras sino también la posesión de compañías productoras por parte de extranjeros. Estos hechos contribuyeron a consolidar una industria netamente nacional y favorecieron el establecimiento de Shanghái como la Meca del cine chino. Por otra parte, permitieron que Hong Kong jugara un papel importante en la naciente industria y que favorecida por las circunstancias históricas tomara su propia ruta unos años después. Pero también forjaron las difíciles condiciones bajo las que operó la industria de cine en Taiwán.

La primera época dorada del cine chino fue interrumpida primero por la 
segunda guerra contra los japoneses en 1937, después por la Segunda Guerra Mundial y finalmente por la guerra civil entre nacionalistas y comunistas. Transcurrieron siete años en los cuales parte de la industria que permaneció en Shanghái se estancó y la otra parte se trasladó a otras ciudades de China y, en particular, a Hong Kong. Lo interesante es que durante la invasión, los japoneses impulsaron su propia industria de cine en los territorios chinos ocupados para producción y consumo de películas tendientes a desarrollar el concepto de Daitoa kyoeiken, con el cual el gobierno japonés expresó su deseo de crear un bloque de naciones asiáticas lideradas por Japón y libres de la influencia occidental (Yau 162). Para tal efecto, los japoneses establecieron varias compañías de cine en los territorios ocupados de Manchuria, Shanghái y Nanjing. Mientras que las políticas de su gobierno tendían a politizar las producciones de cine chino a partir de la eliminación del sentimiento antijaponés, el sentir y accionar de los cineastas japoneses en territorios ocupados era otro. Les interesaba más abrir nuevos mercados a lo largo de Asia que los conflictos políticos entre Japón y China, y hasta sentían admiración y simpatía por el cine chino. Lo que los chinos interpretaron como intentos del imperio japonés por controlar su industria de cine, junto con las atrocidades cometidas por el ejército japonés en territorios invadidos, motivaron el surgimiento de un nuevo género de cine chino: las películas de defensa nacional.

Cuando termina el intervalo de siete años que transcurre entre el comienzo de la segunda guerra sino-japonesa y el fin de la guerra civil entre nacio- nalistas y comunistas, surge un bando ganador indiscutible. Como resultado, el KMT huye a la isla de Taiwán, colonia japonesa desde 1895 hasta 1945. Es decir, colonia japonesa desde que la última dinastía china la cediera al imperio japonés al ser derrotada durante la primera guerra sino-saponesa, pero solo hasta que Japón fuera derrotado durante la Segunda Guerra Mundial y perdiera control sobre Taiwán. La colonización japonesa había estampado un claro sello cultural en el cine que se consumía en la isla hasta ese entonces. Chen Feibao discute que una industria de cine comienza a operar en Taiwán en 1923 con la llegada de dos compañías de cine (citado en Yue 215). Consistente con el posterior papel de los japoneses en el cine de los territorios ocupados de China durante la segunda guerra sino-japonesa, en Taiwán se dio un fuerte adoctrinamiento de la población local por parte de los japoneses. Este panorama cambió con el nuevo gobierno del KMT, el cual no solo prohibió el cine hablado en japonés o que explotaba temas culturales japoneses, sino que también con el deseo de evitar la experiencia del cine de izquierda en China continental durante la primera época de oro de su cine, decidió regular fuertemente la producción audiovisual en Taiwán. Así se elevaron los impuestos al equipo, a los rollos de película y hasta a las entradas de cine (Udden 124). Por otro lado, al igual que la industria de cine de Hong Kong, la de Taiwán sufría por la competencia con la industria de Shanghái. Sin embargo, consciente de la influencia del cine en las masas, en los años 50 el gobierno nacionalista revivió la industria de cine taiwanesa con la adquisición de equipo más moderno, importación de nuevas 
técnicas de cine, diversificación de géneros y distribución más eficaz a lo largo del territorio nacional. Esto se hizo con el fin de producir identificación con los símbolos de la Madre Patria de la cual se habían exiliado y para incitar recuerdos visuales de la etnia Han a la que pertenecían. Durante la siguiente década, el estudio Zhongyang dianying zhipianchang, patrocinado por el gobierno, se consolida como el estudio más grande en Taiwán. Las películas producidas en mandarín viven una época dorada gracias a la contratación de talento de China continental, lo cual contribuye a controlar el mercado durante los años sesentas y setentas.

Mientras la industria de cine de Taiwán sufría de severos recortes y de las políticas intervencionistas del estado taiwanés, la industria de cine de Hong Kong florecía. Sin embargo, antes de que se produjera este florecimiento, la industria de cine de Hong Kong había pasado por sus puntos bajos. Según Teo, en comparación con la industria de cine de Shanghái, esta tenía reputación de industria regional (10). Además, los cineastas y artistas que se habían refugiado en Hong Kong durante la segunda guerra sino-japonesa eran de izquierda, por lo que la despreocupación política de sus congéneres del sur tornaba a los primeros desdeñosos e intolerantes hacia los segundos. Por último, la decisión del gobierno central chino en 1937 de vetar el cine hablado en el dialecto cantonés del sur, dio la estocada final a la moral ya baja de la industria de cine de Hong Kong. Esto cambió cuando la guerra civil (1941) y la política de puertas cerradas de China continental (1949) contribuyeron en gran parte a transformar la industria en el territorio. Una nueva ola mi- gratoria desde Shanghái atrajo hacia el sur a figuras clave en la formación de una industria de cine más sofisticada y experimentada. Estudios como Yonghua (1947), Changcheng (1949) y Da Zhonghua (1946) comenzaron a producir filmes hablados en mandarín, caracterizados por ser grandes producciones con mucho brillo y glamur, y eran esencialmente dirigidos a audiencias continentales. Cuando este mercado se cerró, la industria encontró otros clientes: Malasia, Singapur, Taiwán y comunidades de chinos de ultramar en Occidente. Tuvieron que transcurrir casi dos décadas en aislamiento antes de que el cine de Hong Kong desarrollara su propia personalidad y estilo. Mientras eso ocurría, la industria experimentó con el género de musicales (un género establecido y muy reconocido en el norte), que para Teo es la prueba de que Hong Kong absorbió a Shanghái y no solo eso, hasta llegó a imprimirle un sello local con sus propias estrellas de habla cantonesa, su música en lengua vernácula y sus temáticas propias.

Para el año 1972, la industria de cine de Hong Kong había optado por producciones de corte realista con algunas concesiones según la demanda de otros géneros bastante populares como los melodramas familiares, las tragedias pasionales de corte épico (wenyi pian), las artes marciales, la ópera y las farsas pícaras (fenyue). Esta ruptura coincidió con el acelerado crecimiento económico de Hong Kong gracias a su industria textilera, a la influencia occidental que había permeado la idiosincrasia del hongkonés a lo largo de dos décadas de puertas cerradas, y a que las primeras generaciones de hongkoneses que nunca habían conocido China continental estaban alcanzando 
la mayoría de edad y, por lo tanto, estaban forjando identidades únicas $\mathrm{y}$ diferentes de las generaciones anteriores. A raíz de este relevo generacional surge una serie de cambios. Emergen cineastas innovadores como Lung Kong, Tang Shuxuan y Michael Hui quienes reinventan el cine hablado en cantonés, experimentan con técnicas de cine, mezclan géneros, desarrollan temas controversiales que surgen con los nuevos estilos de vida, le dan un nuevo tratamiento a forma, contenido y personajes y reivindican el uso del cantonés en películas tipo A. Las condiciones estaban preparadas para el cine de nueva ola.

\section{Desarrollo del cine en la China post-Mao}

La muerte de Mao Tze Tung en 1976 coincide con la transformación de Hong Kong y Taiwán en economías emergentes en Asia. Mientras que en Hong Kong la industria textilera local contribuye enormemente a que el territorio florezca, en Taiwán el sector del agro apoya una exitosa industrialización fuertemente supervisada por el Estado, que a la larga hace posible su boom económico El sucesor y acérrimo enemigo de Mao, Deng Xiaoping, consciente de la necesidad de un cambio en la República Popular China, implementa una reforma económica que la transforma en una economía de mercado socialista, toda una contradicción pero que en el caso particular de China surte efecto. Esto repercute en la industria de cine de maneras muy productivas. Por primera vez desde 1949, los ingresos de taquilla se convierten en una preocupación de la industria. Así, el cine de propaganda política que tanto se favorece durante la era de Mao, el llamado cine de cuarta generación, va perdiendo terreno para dar paso al cine de la quinta generación Antes de adentrarnos en el cine de olas en las tres industrias chinas, es conveniente hacer un recuento del debate que se suscitó en la industria de cine continental a raíz de las reformas económicas

El surgimiento de un cine de entretenimiento se contrapone a la noción socialista de que el propósito fundamental del cine es de servir como obra didáctica (Lau 18). Así, a mediados de la década de los ochentas, cineastas, críticos de cine y teóricos se enfrascaron en una discusión de la cual se pueden identificar varios puntos de vista. Mientras que la mayoría concordaba en que el cine de entretenimiento es un producto de la economía de mercado y de que una gran parte de estos filmes eran de baja calidad, en otros puntos hubo divergencia. Para algunos, el hecho de que el cine de entretenimiento fuera un medio masivo de influencia era de hecho un punto a favor de voces prosocialistas. Para otros, el hecho de que este tipo de cine sea un producto del capitalismo era ideológicamente problemático. Por eso proponían que en lugar de utilizar las producciones de Hollywood como un modelo para el cine de entretenimiento, se favoreciera la tradición china de elevación moral y purificación emocional. En lo que la mayoría si parecía concordar era en el principio de yia xu kuo xian (alcanzar tanto audiencias promedio como las más demandantes) para el cine de entretenimiento. Sin embargo, dice Lau, el incidente de la plaza de Tiananmen en 1989 repercutió en esta apertura inicial de modo que se reinstauró el 
principio de didacticismo en el cine que dominó las producciones de cuarta generación.

\section{Surgimientodelasnuevasolas: Chi- na continental, Taiwán y Hong Kong}

Llama la atención que el llamado cine de nueva ola o cine vanguardista en China continental, Hong Kong y Taiwán surge casi al mismo tiempo, aunque por razones muy disímiles. La década de los ochentas parece ser ese periodo decisivo en que el cine chino se transforma en las tres regiones.

Por un lado, la quinta generación de China continental produce cine de contenido profundamente político pero de una manera más estética. El término "político" en este caso no se refiere a propaganda o ideología. Parafraseando a Trihn T. Minh Ha, existe una diferencia entre producir cine político y producir cine políticamente: "We are moving here from the making of a genre of film to the making of a wide range of genres of film in which the making itself is political" (147). Esta gran diferencia es precisamente lo que distingue el cine arte creado por los cineastas de quinta generación y el de sus predecesores de la cuarta generación. Las experiencias vividas por los cineastas de la quinta generación y sus contemporáneos moldearon de cierta manera su visión de mundo y crearon una conciencia crítica notable en sus obras. Estos hombres eran apenas adolescentes cuando estalló la Revolución Cultural en 1966, un acontecimiento político que causó cicatrices síquicas, convirtió a algunos de ellos en huérfanos, les denegó un desarrollo educativo normal, los exilió al campo para ser "re-educados" y los obligó a tornarse en contra de la cultura china tradicional, sus mayores y los valores confucianos que habían definido su sociedad hasta entonces (Clark 133). Es decir, posiblemente provocó traumas que después sanarían a través de sus obras artísticas. Estos cineastas son graduados de la Academia de cine de Pekín, reabierta después del fin de la Revolución Cultural en 1976. Estudiaron desde 1978 hasta 1982. Sus intentos por modernizar el cine chino, que durante la época de Mao servía el propósito de difusión de mensajes ideológicos y propaganda, los llevaron a crear cine de nueva ola. Así, el interés de este grupo en temas históricos los llevó por la senda del comentario social de viejas realidades vistas con un ojo crítico post-Revolución Cultural. Si bien Uno de los ocho (Yige he bage, 1983), del director Zhang Junzhao, es considerado como el primer filme de esta generación, el primero aclamado por la crítica es Tierra amarilla (Huang tudi, 1984), de Chen Kaige. Además de cavar en las profundas raíces históricas del pueblo chino con el fin de provocar lecturas recalcitrantes contemporáneas, el grupo desarrolló un estilo visual distintivo, un lenguaje de cine cargado de alegorías y simbolismos, y una gran habilidad para narrar historias en sus películas. De hecho, la estética de la quinta generación se puede resumir en fotografía que tiende a producir efectos desfamiliarizantes en los espectadores chinos. Esta se alimenta de encuadres inusuales, un montaje más activo y expresión simbólica que atenta contra nociones tradicionales de la realidad (Ning y Sklar 34-35).

Sin embargo, acostumbrados a un cine de propaganda socialista, las audiencias nacionales reaccionaron con 
incomprensión y desinterés. En efecto, el lenguaje de cine de la quinta generación supuso un quiebre tan radical que hubieran fracasado de no ser por la atención que estos cineastas y sus asociados comenzaron a generar en festivales de cine internacional. En especial, se destacan Chen Kaige y Zhang Yimou, quien antes de lograr la fama como director estelar, fungiera como director de fotografía de Chen. $\mathrm{Y}$ aunque Chen fue el primer director aclamado de la quinta generación, Zhang produjo más filmes aclamados internacionalmente como Sorgo rojo (1987), La semilla de crisantemo (1990) y Eleven la linterna roja (1991), todas basadas en novelas chinas, pero quizás la más conocida es Sorgo rojo, novela del Premio Nobel 2012, Mo Yan. Otro detalle importante de estos filmes es que la protagonista es la actriz Gong $\mathrm{Li}$, reconocida en el mundo occidental por su papel en Adiós a mi concubina, filme de Chen Kaige que en 1992 compitió en la categoría de mejor película extranjera. Algunos críticos creen que el fin formal de la quinta generación como tal se da a finales de la década de los ochentas. Pese a ello, tanto Chen como Zhang continuaron produciendo cine arte y Zhang en especial adaptó sus películas a gustos más comerciales con Héroe (2002), La casa de las dagas voladoras (2004) y La maldición de la flor dorada (2006). Otros directores de quinta generación menos conocidos en Occidente son Zhang Junzhao, Tian Zhuangzhuang, Wu Ziniu, Zhou Xioawen y Guo Fangfang, cuyas producciones lamentablemente no han capturado la atención de la crítica internacional y no han encontrado un nicho en el mercado global del cine.

Por otro lado, la nueva ola de Tai- wán surge a principios de los ochentas entre cineastas hastiados de los trillados géneros y temas del cine de Taiwán de las décadas anteriores. Argumenta Stephanie Hoare que los cineastas de Taiwan xin dianying, como se les conoce en chino, se diferencian del cine dominante de los años sesentas y setentas en que, primero, deseaban producir cine arte $y$, segundo, que se propusieron provocar la reflexión en su público. Para ellos, el cine dominante se basaba demasiado en emociones predecibles y en convenciones que manipulaban al público. Es decir, era un cine maniqueo que proyectaba un mundo pintado en blanco y el negro en el cual siempre triunfaba el bien sobre el mal y las nociones de lo bello, lo bueno y lo verdadero estaban fijadas por una lógica en donde no cabía la ambigüedad ni la polivalencia de significados.

Una de las características del nuevo cine es la adaptación de literatura reflexiva de Taiwán, una corriente que surge en los años 50 y que provoca rupturas con los relatos nostálgicos sobre China continental escritos por autores continentales en exilio y relatos de romances y de héroes de artes marciales escritos en una combinación de mandarín estándar y chino clásico (Hoare 34). Esta nueva literatura desarrolla otras vertientes que desembocan en la literatura del terruño de los años 60 y 70. Mientras que parte de la nueva literatura desarrolló realidades subjetivas del individuo, otra parte se dio a la tarea de reflejar problemáticas sociales e historias de la gente común de Taiwán. Rupturas significativas se dan no solo en la literatura taiwanesa sino también en el cine, aunque estas últimas se dan varias décadas después. Hasta la aparición de la generación del 
nuevo cine de Taiwán y de los nuevos directores acuciosos (xinrui daoyang), como los denomina Hoare, los géneros de cine más populares eran los melodramas contemporáneos de Qion Yao (la Corín Tellado taiwanesa), las historias de artes marciales de épocas pasadas y filmes de propaganda del gobierno taiwanés.

Otra característica es la búsqueda de la objetividad por medio de técnicas narrativas poco tradicionales: se evita el uso de música, diálogo o close ups para manipular las emociones de los espectadores. Muy por el contrario, se enfatiza el ambiente y los silencios como una forma de significar y de producir respuestas más activas por parte del espectador. La tercera característica se refiere a la habilidad del nuevo cine de Taiwán de reflejar con más precisión realidades contemporáneas, lo cual se aleja significativamente de la fantasía enlatada de la visión dominante de la realidad. Así, el nuevo cine se dio a la tarea de denunciar la pobreza, la inequidad social, política y económica entre el campo y la urbe, la desigualdad de género y otras formas de opresión, tal y como en su momento lo hizo la literatura reflexiva. La última característica del cine nuevo es su uso de significantes locales que se pueden apreciar en el lenguaje y las locaciones. Esto supuso una nueva ruptura con el modo dominante de producción cultural, a la vez que contribuyó a reivindicar dialectos de la isla tales como el taiwanés o el fukianés y, en el caso del taiwanés, le da mayor precedencia al lenguaje oral que al escrito y, por lo tanto, privilegia la cultura popular sobre la cultura elitista que connota el mandarín como lengua oficial de Taiwán. Con respecto a las locacio- nes, se da un gran cambio que incluye filmación en lugares reales, fuera del estudio y de la urbe. También, se incorporan costumbres locales que en ocasiones no aparecían en el guion original y miembros de la comunidad que actuaban "naturalmente" y, por ende, añadían autenticidad al relato.

Un hecho que la crítica de cine ha descubierto es el papel fundamental que jugó el veterano cineasta Hou Hsiao Hsien en el surgimiento de la primera ola de Taiwán. Al contrario de otros directores de la nueva ola como Edward Yang, Wan Jen, Tseng Chuang Hsiang y Ko Yi Cheng, Hou no estudió cine formalmente en academias en el extranjero ni comenzó su carrera como director. Hou tampoco pertenecía a la misma generación que esos directores cuyo fin primordial era producir filmes con una visión estética, y de hecho comenzó su carrera en condiciones diametralmente opuestas a las de sus privilegiados colegas. Por un lado, Hou inició su aprendizaje en cine comercial durante los años sesentas, cuando aún existía mucho control estatal y debió comenzar desde abajo, primero como continuista, asistente de dirección y guionista antes de dirigir su primera película (Wen 212), lo cual fue en realidad una gran ventaja en su posterior desarrollo como director de la nueva ola pues fue en esa variedad de roles donde Hou aprendió todos los trucos que después harían de él un gran cineasta. Así, sus producciones tienden a ser más políticas, más estéticas y hay mayor experimentación técnica, pero paradójicamente debido a los recortes presupuestarios con que lidiaba la industria debido al excesivo control estatal.

Dice James Udden que es en el cine comercial de Taiwán donde puede 
apreciarse el aprendizaje un tanto "extraño" de Hou Hsiao Hsien. Los creativos intentos por parte de los cineastas taiwaneses de los años 60 y 70 por maximizar los pocos recursos con los que contaban originaron una serie de técnicas que Hou recogió y reinventó en sus producciones de la nueva ola. Entre ellas se mencionan los juegos de luces, los acercamientos rápidos, la experimentación con tomas y la reducción del radio de captura, todas ellas técnicas que surgieron para evitar el uso innecesario de celuloide o de otros recursos (Udden). Lo que Hou aprendió durante esos años se manifestó a partir de 1983 en un estilo artístico que incluye tomas inusualmente largas, impresionantes diseños de luces y narrativas elípticas pocas veces vistas en la historia del cine. Hou comenzó en la tradición del nuevo cine de Taiwán con la trilogía Hombre emparedado (1983), la cual dirigió junto con dos de sus nuevos colegas: Wan Jen y Tseng Chuang Hsiang. Pero quizás los filmes que más reconocimiento le han valido a Hou son Tiempo para vivir, tiempo para morir (1985) y la controversial trilogía sobre la historia de Taiwán, Una ciudad de tristeza (1989), ganadora de un León Dorado del Festival de Cine de Venecia; así mismo, Maestro titiritero (1993), premio del jurado en Cannes y Hombres buenos, mujeres buenas (1995), la única película que irónicamente no fue ignorada en la premiación local de cine pero que pasó inadvertida en festivales internacionales.

En Hong Kong, el surgimiento de una cultura popular autóctona en los años setentas hizo posible el cine de la nueva ola. Los hermanos Sam y Michael Hui explotaron el uso del cantonés en un género musical nuevo, el cantopop, que se convirtió en la bandera de una generación de jóvenes ávida por manifestaciones culturales propias creadas e interpretadas por sus propios ídolos en su propia lengua. Muchas de estas estrellas saltaron del canto a la actuación y con ello comenzó una tradición de entrecruce de géneros. Los hermanos Hui constituyen un buen ejemplo pues Sam interpretaba los temas musicales de las películas de Michael, actor y director de cine, mientras que este contribuía a componer los temas de su hermano. De su filme Cenizas inquietas, dice Stephen Teo que es el primero en Hong Kong en "mostrar una nueva forma basada en edición libre, fotografía realista en locación y un ritmo más rápido del usual" (145). Sin ser una producción de primera ola, algunos críticos la han tildado de "pre-ola" pues abrió el camino para directores de la primera ola como Ann Hui, Alex Cheung, Tsui Hark, Yim Ho, Patrick Tam, Peter Yung y quizás el más conocido en Occidente, John Woo. En 1979, el año que se considera como el inicio del periodo de las nuevas olas en Hong Kong, ellos comenzaron a expresar sus preocupaciones en cine de autor. Así, utilizaron el cantonés activamente mientras descubrían un nuevo lenguaje fílmico que se manifestó en temas sociales y un estilo innovador. El cine de primera ola está fuertemente definido por el cine de acción: elaboradas coreografías aéreas, artes marciales, efectos especiales de Hollywood, balaceras, explosiones, tomas en cámara lenta de héroes protegiéndose de ataques enemigos, todos ellos deliberadamente orquestados en una variedad de maneras para crear un violento ballet de gran esteticismo fotográfico. El cruce de géneros se manifiesta en historias que 
combinan cine de acción con artes marciales, comedia romántica o historias de lo sobrenatural y en personajes pandilleros con códigos morales propios de héroes de artes marciales.

Con la aparición de un público más exigente y más educado, se profesionaliza la televisión y el cine locales y consecuentemente se eleva la calidad de las producciones audiovisuales. Surge una segunda nueva ola de cine en Hong Kong a finales de los años 80 con directores que habían servido de asistentes de algunos directores de primera ola. De esta segunda ola destaca una mayor madurez estética y una mayor experimentación formal. Tal es el caso del director más reconocido internacionalmente de esta generación, Wong Kar Wai, quien comenzó su carrera trabajando para Patrick Tam. Si bien algunas de las primeras producciones de Wong muestran apego hacia el género de acción, supo trascender la influencia de su mentor, experimentó con otros géneros y se adentró en cuestiones de identidad de cara a la inminente devolución de Hong Kong. En particular, Wong desarrolló dos técnicas que contribuyeron a expresar su preocupación por el destino de Hong Kong después de 1997: el momento perdido y las emociones retardadas, técnicas que utiliza en su trilogía no oficial que algunos llaman "Hong Kong en los sesenta" y otros "Amor en los sesenta": Días de libertinaje (1990), Queriendo amar (2000), premio de Cannes, y 2046 (2004). Pero, además, utiliza mucho la cámara lenta, los intertítulos y la literatura y se distingue por una fotografía impecable, guiones bien elaborados y su obsesión por editar una y otra vez hasta lograr la perfección. Debido al entrecruce de géneros en la escena ar- tística de Hong Kong y al sistema de estrellato local, es común ver en sus filmes caras tan conocidas como Leslie Cheung, Brigitte Lin, Tony Leung, Maggie, Cheung, Jackie Cheung y Faye Wong, así como a artistas de la China continental como Gong Li y Zhang Ziyi.

\section{Conclusiones}

El llamado "cine chino" nace como una empresa con matices transnacionales y translocales que reúne talento de Shanghái con capital foráneo. Sin embargo, en sus inicios es difícil separar los elementos culturales chinos de cada una de sus vertientes: la continental, la taiwanesa y la de Hong Kong. La separación más obvia comienza a gestarse solo a partir de la década de los 70. Si el cine de quinta generación supuso un quiebre ideológico y estético con el cine comunista de la era de Mao, y el cine nuevo de Taiwán surgió a partir de una mezcla de nuevas realidades sociales en la isla y de una liberalización de la industria de cine local, el cine de nueva ola de Hong Kong emerge, también en los 80 , a partir de procesos de formación de nación e identidad propios del territorio. El establecimiento del régimen comunista de China continental tuvo efectos muy diferentes para taiwaneses y hongkoneses de origen chino, dos grupos étnicos fuertemente ligados a la madre patria. Mientras que la derrota en condiciones vergonzosas de las fuerzas de Chiang Kai Shek ante los comunistas definió las políticas de intervencionismo estatal que caracterizaron todas las industrias taiwanesas, incluida la de cine; la política de puertas cerradas detuvo un flujo migratorio, ideológico 
y cultural entre Hong Kong y el continente que a la larga contribuyó a reforzar significantes locales como la lengua vernácula, el cantonés, la ópera Yue, el cantopop y otras manifestaciones culturales que dieron origen a una mayor conciencia local y a un mayor apoyo en su propia cultura local. Esta particularidad le dio al cine de Hong Kong un carácter cuasinacional paradójicamente basado en la explotación de lo local.

De esta manera, se puede afirmar que los tres cines son similares debido a que surgen en momentos cruciales de quiebre con el pasado. Este relativo estado de libertad los conduce a la búsqueda de nuevas identidades por medio de la experimentación y la innovación. A raíz de ello logran el reconocimiento de la crítica y del canon cinematográfico y esto los consolida como cines de carácter nacional. Así, en la actualidad cada uno posee una industria propia y distintiva. Sin embargo, es necesario reconocer que ninguna de estas industrias habría prosperado si primero no se hubiera producido un crecimiento económico en cada sociedad, es decir, si no se hubieran insertado en las actuales conversaciones de la sociedad capitalista.

\section{Bibliografía}

Clark, Paul. "Reinventing China: The Fifth-Generation Filmmakers." Modern Chinese Literature. Vol. 5, No. 1. Special Issue on PRC literature of the eighties. (Spring 1989) 129-36.

Curry, Ramona. "Benjamin Brodsky (1877-1960): The Trans-Pacific American Film EntrepreneurPart One Making a Trip Thru
China." Journal of American EastAsian Relations. 18 (2011) 58-94.

Dai, Jinhua. Trad. Jingyuan Zhang. "Hou Hsiao Hsien's films: Pursuing and Escaping History." Inter Asia Cultural Studies. Vol. 9, No. 2. 2008. 239-50.

Hoare, Stephanie. "Innovation through Adaptation: The Use of Literature in Taiwan New Cinema and Its Consequences." Modern Chinese Literature. Vol. 7, No. 2. Special Issue on Filming Modern Chinese Literature. (Fall 1993) 33-58.

Kwok Wah-Lau, Jenny. "Farewell my Concubine: History, Melodrama and Ideology in Contemporary PanChinese Literature." Film Quarterly. Vol. 49, No 1. (Fall 1995) 16-27.

Ma, Ning y Robert Sklar. "New Chinese Cinema: A Critical Account of the Fifth Generation." Cineaste. Vol. 3, No. 17 (1990) 32-5.

Udden, James. "Taiwanese Popular Cinema and the Strange Apprenticeship of Hou Hsiao-hsien." Modern Chinese Literature. Vol. 15, No. 1. Special Issue on Taiwan Film. (Spring 2003) 120-45.

Wen, Tien Hsieng. Trad. Sheo Hui Gao. "Hou Hsiao Hsien: A Standard for Evaluating Taiwan Cinema." Inter Asia Cultural Studies. Vol. 9, No. 2 (2008) 211-38.

Yau, Shuk Ting Kinnia. "The Early Development of East Asian Cinema in a Regional Context." Asian Studies Review. Vol. 33 (junio 2009) 161-73. Zhang, Yingjin. "Transnationalism and Translocality in Chinese Cinema." Cinema Journal. 49, No. 3 (Spring 2010) 135-39. 